\title{
Batch Fabricated Inline Microfluidic Valve
}

\author{
P. Selvaganapathy, E. T. Carlen and C. H. Mastrangelo \\ Center for Wireless Integrated Microsystems \\ Department of Electrical Engineering and Computer Science \\ University of Michigan, Ann Arbor, MI 48109-2122, USA.
}

\begin{abstract}
A normally open electrothermally actuated inline microvalve that has been developed, fabricated and tested with liquids is presented. The inline valve is surface micromachined on top of flexible microfluidic channels using a low temperature fabrication process; therefore it is suitable for integration with microfluidic networks requiring actuation of a large number of valves under electrical control. Complete closure of sealed microchannels has been observed with power as low as $40 \mathrm{~mW}$. Response times of $15 \mathrm{msec}$ have been measured. Breakdown of the inline valve occurs at an upstream pressure of 23 psig.
\end{abstract}

\section{INTRODUCTION}

Emerging microfluidic systems involve the integration and automation of many individual steps performed in macroscale biochemical analysis $[1,2,3]$. This requires the ability to control precisely and efficiently the transport of reagents and samples throughout different parts of the system. Typically these systems require many valves operating simultaneously or in sequence. Therefore, the valve actuators must be small operating with low power, and must integrate easily with the system components.

Over the past decade, there has been wide variety of actuation mechanisms and methods employed for construction of microvalves including electrostatic, magnetic, piezoelectric, bimorph and thermopneumatic actuation [1]. Some of these techniques employ bulk micromachining and anodic bonding, making the valves large, out of plane and difficult to integrate in large scale in microfluidic systems.

In this paper, we present a simple microfluidic valve that is easily integrated with other fluidic components on the same die. Thermopneumatic actuation was chosen for this valve because it holds several advantages over other actuation schemes. Most actuation methods provide either large displacements or large forces. Shape memory alloys provide both large actuation and displacements but can be difficult to integrate and do not conform to the shape of the channel [4]. Thermopneumatic actuation provides both large displacements $(2-10 \mu \mathrm{m})$ and forces $(\sim 1 \mathrm{~N})$, and with the recent published method [5] for batch fabrication compatible with microfluidic systems, is ideal for this application. The thermopneumatic actuators used as the active elements of the microvalves presented here are based on the phase change expansion of a sealed surface micromachined patch of paraffin.

\section{DEVICE DESIGN}

The actuation mechanism depends on a thermally triggered phase change in the paraffin actuation material resulting in a volumetric expansion. Paraffin is a linear hydrocarbon mixture of alkanes of varying chain lengths, with high volumetric expansion upon phase change from solid to liquid. It also has other desirable properties such as, low thermal and electrical conductivity, low viscosity in liquid phase and stability through numerous phase change cycles. Typically volumetric expansion between 10-30\% can be achieved when heated at temperatures ranging from 65$150^{\circ} \mathrm{C}$, depending on the melting temperature of the material. Figure 1 shows the pressure-volume-temperature (PVT) characteristics of the paraffin material used in the devices (bonding wax, Logitech Ltd, (0CON-175) with a melting temperature of $72^{\circ} \mathrm{C}$.

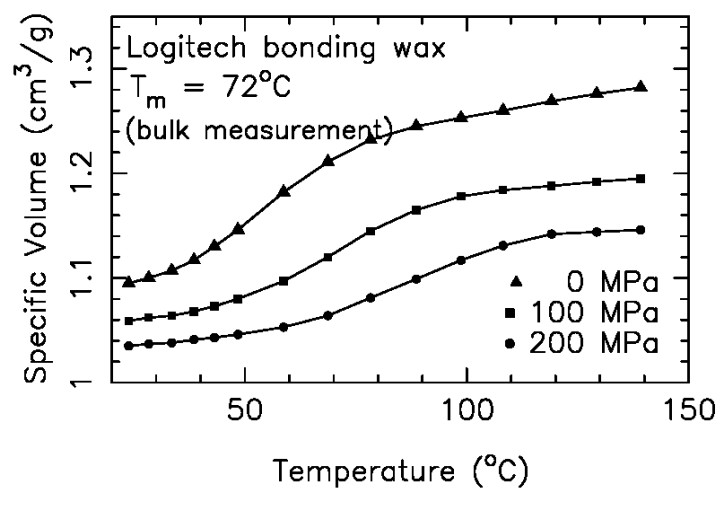

Figure 1: PVT of Logitech OCON-175 bonding wax

Figure 2 shows the top view of the inline valve with a paraffin microactuator. Figure 2a shows a microchannel with a reduced section and heaters on either side of the reduced section. The cross sectional dimension of the microchannel is $10 \mu \mathrm{m} \times 100 \mu \mathrm{m}$ (height $\mathrm{x}$ width). In the reduced section the dimensions are

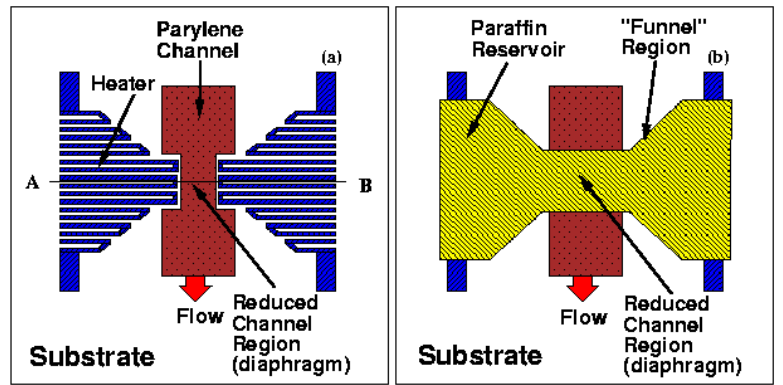

Figure 2: Top view of the microactuator

$1 \mu \mathrm{m} \times(10-50) \mu \mathrm{m}$. The top of this microchannel is constructed from thin $(0.2 \mu \mathrm{m})$ parylene, acting as a diaphragm for paraffin actuation in the reduced section. The heaters on both sides of the channel are patterned and used to melt the paraffin. Figure $2 b$ shows the paraffin micromachined on top of the heaters and the reduced section. The paraffin is then sealed with a thick $(3-4 \mu \mathrm{m})$ parylene layer. The paraffin layer has this unique shape in order to funnel the melted paraffin from the reservoir onto the reduced 
channel region providing hydraulic advantage for maximizing diaphragm deflection. Figure 3 shows a perspective schematic of the valve.

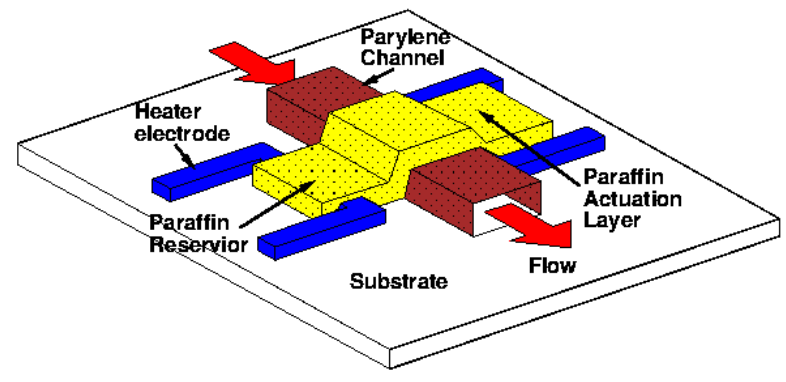

Figure 3: 3-D schematic view of the valve.

The paraffin patch overlaps the reduced region of the microchannel. When the heaters melt the paraffin in the reservoirs it flows into the reduced channel section deflecting the thin diaphragm closing the channel. In order to maximize the deflection, the paraffin reservoir is enclosed by a thick $(10 \mu \mathrm{m}) \mathrm{Ni}$ electroplated layer as shown in Figure 4. The Ni layer prevents the expansion of the paraffin chamber upwards and concentrates the expansion to the diaphragm in the reduced channel region as well as improving the heat transfer to the paraffin. The change in the cross section of the channel at the reduced height channel region is shown in Figure 4.

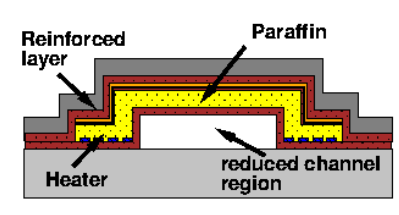

(a)

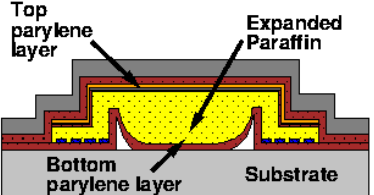

(b)
Figure 4: Cross section of reduced channel region during off and on states

\section{FABRICATION}

The entire microfluidic system including inline valve and microchannel was fabricated using a low temperature process $\left(<90^{\circ} \mathrm{C}\right)$. Figure 5 shows a simplified process flow. Inlet holes to the microchannels were patterned in UV definable glass substrates (Foturan, Schott Corp.). Patterning the Foturan substrates required UV $(312 \mathrm{~nm})$ exposure $\left(\sim 2 \mathrm{~J} / \mathrm{cm}^{2}\right.$ energy density for a through wafer patterning) followed by heat treatment, which reached $600^{\circ} \mathrm{C}$ for 1 hour. During the heat treatment the substrate surface became rough and required surface refinishing. The substrates are then planarized with a $20 \mu \mathrm{m}$ calcined aluminum oxide slurry (0CON012, Logitech, Ltd.) for 1 hour and polished with an alkaline colloidal silica slurry (SF1 0CON-140, Logitech, Ltd.) for 1 hour. The wafer was then cleaned using a piranha clean recipe $\left(\mathrm{H}_{2} \mathrm{SO}_{4}: \mathrm{H}_{2} \mathrm{O}_{2}, 1: 1\right)$ for 20 mins to remove organic residue on the surface. Next, the sacrificial channel except the reduced region and reservoir areas are formed by spin-casting a $10 \mu \mathrm{m}$-thick photoresist (AZ 9260, Clariant) layer followed by softbake $65^{\circ} \mathrm{C}$ for $1 \mathrm{hr}$ ), exposure $\left(5 \mathrm{~mW} / \mathrm{cm}^{2}\right.$ for $110 \mathrm{sec}$ ), and development (1:4 AZ400K (Clariant): $\mathrm{DI}_{2} \mathrm{O}$ for 3 mins). The reduced height region was formed by spin casting photoresist layer $1 \mu \mathrm{m}$ thick (SC 1813, Shipley, Corp.) followed by softbake $\left(65^{\circ} \mathrm{C}\right.$ for 1 hour), exposure $\left(5 \mathrm{~mW} / \mathrm{cm}^{2}\right.$ for $20 \mathrm{sec}$.), and development (MF319, Shipley, Corp).
This layer defines the height and the width of the reduced region. The width varied from $10 \mu \mathrm{m}$ to $50 \mu \mathrm{m}$ for various devices in the die. The entire substrate was then coated with the bottom parylene layer $3 \mu \mathrm{m}$ thick.
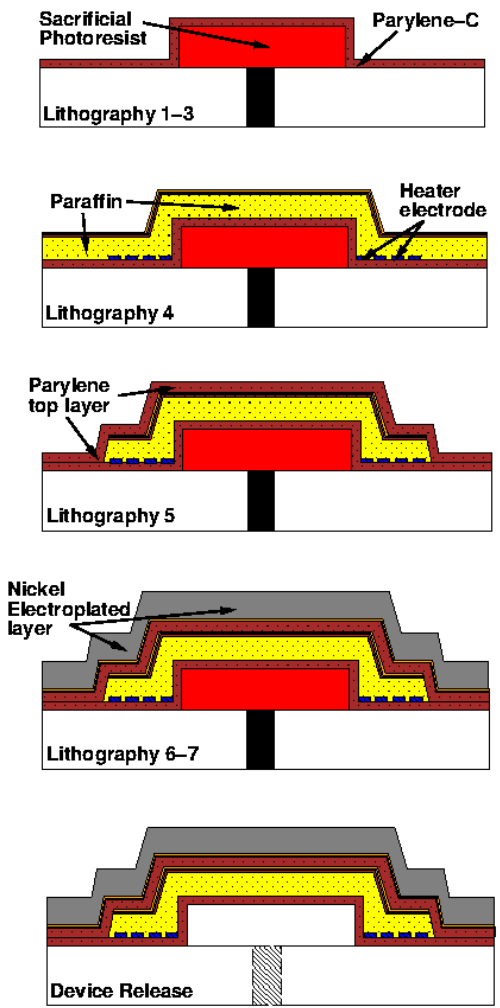

Figure 5: Fabrication process flow for microvalve

Next, $\mathrm{SiO}_{2} / \mathrm{Cr} / \mathrm{Al}(10 / 30 / 500 \mathrm{~nm})$ layers were sputter coated on the wafer. The $\mathrm{Cr} / \mathrm{Al}$ layers were then patterned and wet etched forming the actuator heaters. The $\mathrm{SiO}_{2}$ layer was then removed in the field areas. Paraffin is then thermally evaporated and covered with the parylene/Cr/Au (500/50/300nm) etch mask materials. The $\mathrm{Cr} / \mathrm{Au}$ layers are patterned and parylene/paraffin films were removed using a $\mathrm{CF}_{4}: \mathrm{O}_{2} \mathrm{RIE}$ step. The second parylene layer, 3-4 $\mu \mathrm{m}$ thick, was then vapor deposited and patterned. A Ti/Au $(50 / 500 \mathrm{~nm})$ seed layer for the electrodeposited nickel reinforcing layer was then sputter coated on the sample. A thick photoresist electroforming mold was then spin cast and patterned. A $10 \mu \mathrm{m}$ thick nickel reinforcement layer was then electrodeposited. After the nickel deposition was complete, the photoresist mold was removed with acetone and the exposed $\mathrm{Ti} / \mathrm{Au}$ areas are wet etched.

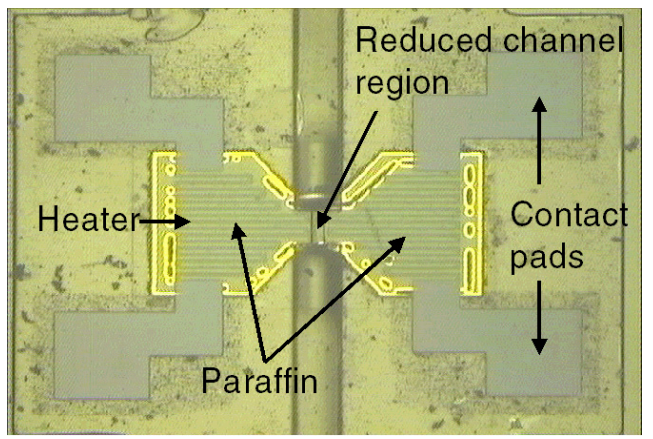

Figure 6: Optical photograph of the backside of the valve 
The Foturan glass substrates were then wet etched (10:1 DI H2O: HF (49\%)) forming the inlet holes while at the same time dicing the wafer. Finally, the sacrificial photoresist was removed in an acetone bath for $2 \mathrm{hrs}$.

Figure 6 shows the backside view through the glass substrate of the fabricated valve. The heaters along with the paraffin on top of them can be clearly seen. Figure 7a shows an SEM photograph of the microvalve along with the microchannel and reservoir. Figure $7 \mathrm{~b}$ shows a closer view of the microvalve from which the reservoir and the reduced channel region can be clearly delineated.
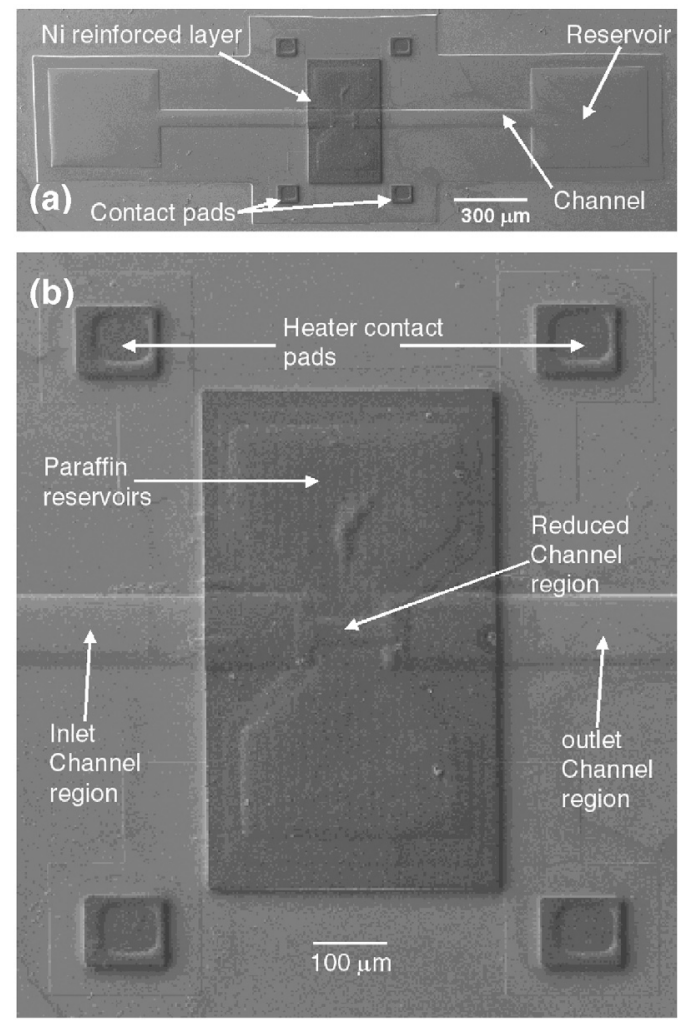

Figure 7: SEM photograph of a) valve channel system and $b$ ) closeup of the microvalve

\section{EXPERIMENTS}

The inline devices were mounted on a custom made microfluidic test fixture shown in Figure 8. The fixture consists of four tapered channels having a gradient in diameter from $1 \mathrm{~mm}$ on the outside connecting to an external fluidic system to $500 \mu \mathrm{m}$ on
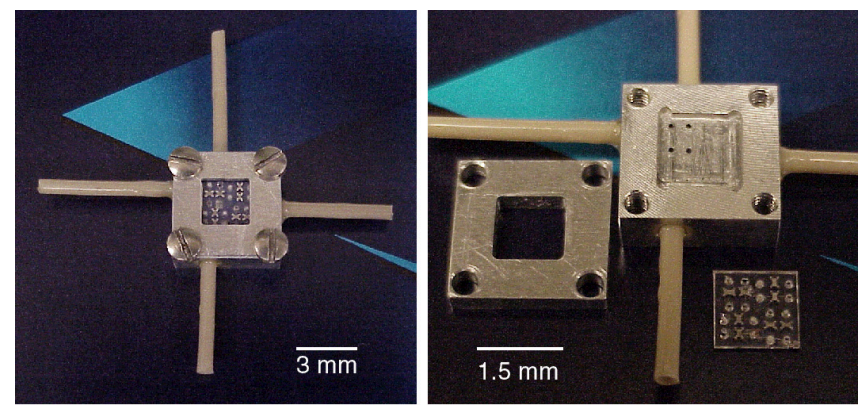

Figure 8: Fixture used to connect the devices to macroscale fluidic control and measurement system a) assembled $b$ ) disassembled the inside connecting to the reservoirs on the die. A silicone rubber O-ring was placed between the fixture and the die. A top plate was used to clamp the die firmly against the O-ring and fixture. This provides a good fluidic seal between the fixture and the die. The top plate has an opening that allows electrical contact of the heaters for testing.

The fixture along with the device were then attached to the fluidic control and measurement system. A schematic of the system is shown in Figure 9. A syringe pump (BAS MD 1001) was used to force the liquid into the microfluidic channel with a controlled pressure control at the inlet channel region. A pressure transducer (Omega PX4600) was used to monitor the pressure at the inlet region. The pressure transducer's output was recorded using a computer.

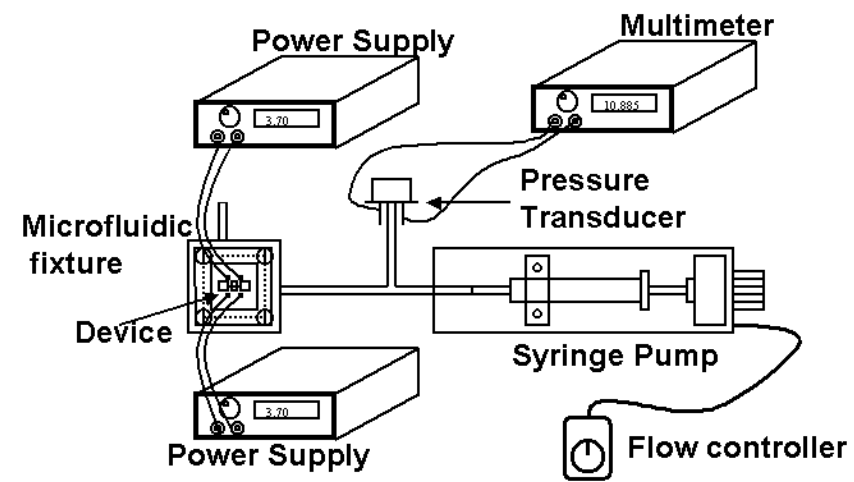

Figure 9: Schematic of the pressure control and monitoring system used for characterization of the valve

The following methodology was used to test the characteristics of the valve. Initially the liquid was pumped through the system into the microchannel and out of the fixture. The valve was then closed, and the pressure in the upstream side of the valve, as monitored by the transducer was allowed to rise to the desired level. The syringe pump is stopped and the power supplied to the heaters was reduced gradually until the valve breaks allowing the liquid to flow through. This produces an accurate measurement of the power required to hold a particular pressure differential across the valve. The liquid used in all the cases was DI water.

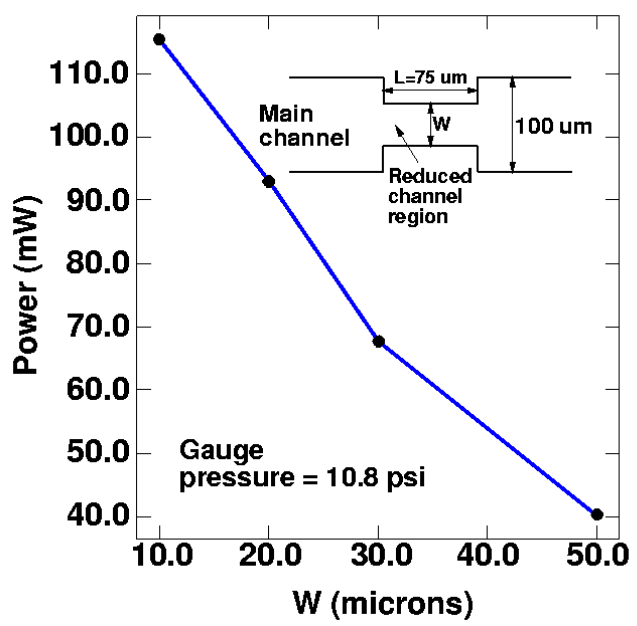

Figure 10: Power required to close a microchannel with variation in reduced channel width 
Several devices with varying reduced channel dimensions from $10 \mu \mathrm{m}$ to $50 \mu \mathrm{m}$ were constructed and tested. The height (1 $\mu \mathrm{m})$ in each case was the same. The pressure at the upstream end was maintained at 10.8 psig and the minimum power required for closing of the valve was measured. The result presented in Figure 10 shows that as the channel width increases the power required to close the valve decreases. An increase in channel width places the supports of the diaphragm farther apart making the diaphragm deflect more for the same pressure. Since the pressure generated on the diaphragm from the expanded paraffin is correlated to the electrical power, more power is required to close channels with smaller widths.

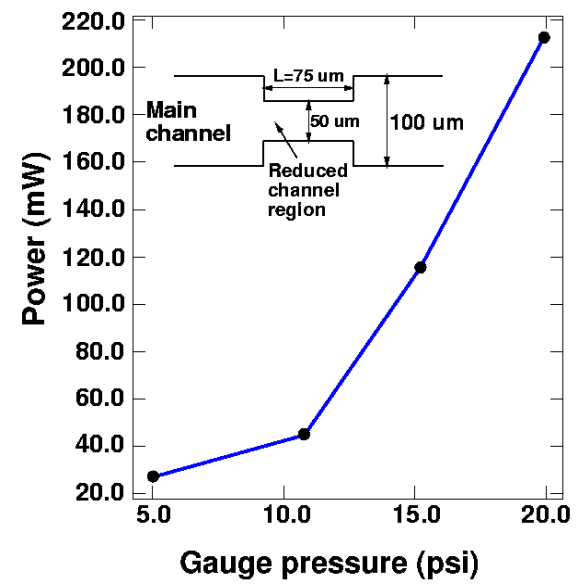

Figure 11: Power required to close a microchannel variation in upstream pressure.

Figure 11 shows measurements of the power required to close a microchannel with $50 \mu \mathrm{m}$ reduced channel width for different upstream pressures. It shows that higher power is required for closing channels with higher upstream pressure. Figure 12 shows the transient response of the valve when it opens. Typically the cooling of the molten paraffin determines the response time of the valve, which can be indirectly correlated using the opening characteristics. The valve closing required $50 \mathrm{~mW}$ of power, and the upstream pressure was maintained to be slightly above $10 \mathrm{psig}$. The valve opened in about $15 \mathrm{~ms}$.

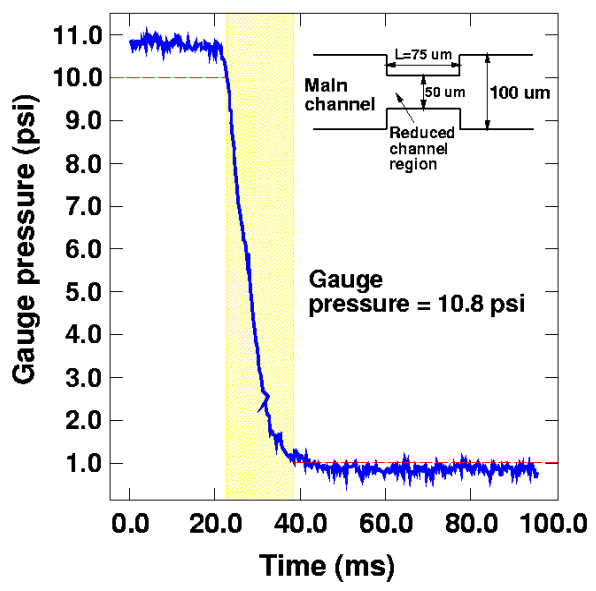

Figure 12: Transient response of the upstream pressure to valve opening

One dimensional steady state and transient simulations on the device were performed using ABAQUS FEM software. The temperature at the surface of the electroplated Nickel was also measured using an IR camera (Inframetrics, Inc. SC 1000) for varying power. This measurement was used in simulations to determine the heater surface temperature with respect to the power delivered to the heaters as shown in Figure 13. Figure 13 shows that phase change occurs at power as low as $30 \mathrm{~mW}$. Furthermore simulations were performed, to determine the transient response of the device at various heater temperatures, which matched experiments. The inline valve device was found to undergo structural failure above 23 psig. The failure occurred either due to the loss of adhesion between the parylene channel reservoirs when the upstream pressure is increased or due to the loss of adhesion between the top and bottom layers of parylene of the paraffin reservoir due to expansion of paraffin at above $300 \mathrm{~mW}$. This caused a leakage of paraffin outside its reservoir.

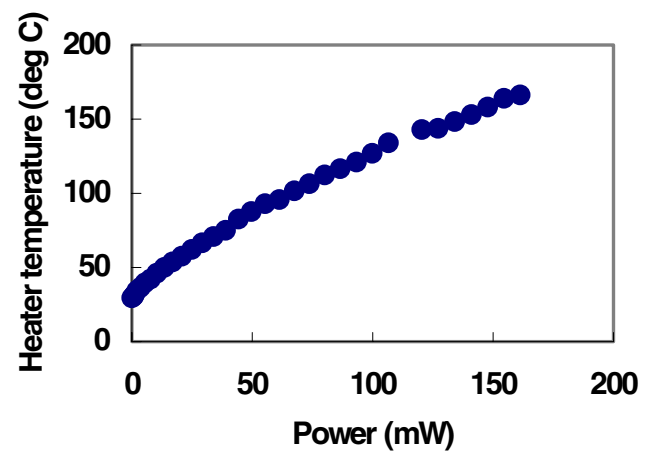

Figure 13: Simulated heater temperature vs. power delivered

\section{CONCLUSIONS}

In this paper we presented the design, fabrication and testing of an electrothermally actuated, normally open, inline microvalve for microfluidic applications. Actuation was performed by a thin paraffin layer as a thermally activated phase change material. The novel construction uses the top layer of the flexible parylene channel as the diaphragm, which is actuated by the expansion of a paraffin reservoir. The valve is constructed using a simple, low temperature fabrication process. The inline valve device is especially suitable for microfluidic systems where a large number of valves are required under electrical control.

\section{ACKNOWLEDGEMENTS}

This work is supported by DARPA grant under contract F30602 98-2-0197

\section{REFERENCES}

[1] S. Shoji and M. Esashi, "Microflow devices and systems," J. Micromech. Microeng., vol. 4, pg. 157-171,1994.

[2] M. A. Burns et al., "An integrated nanoliter DNA analysis device," Science, vol. 282, pg. 253-258, 1998

[3] D. J. Harrison, et al., "Capillary electrophoresis and sample injection systems integrated on a planar glass chip," Anal. Chem., vol.64, pg. 1926-1932, 1992.

[4] P. Krulevitch, et al., "Thin film shape memory alloy microactuators," JMEMS, vol. 5, pg. 270-281, 1996.

[5] E. T. Carlen and C. H. Mastrangelo, "Simple, high actuation power, thermally activated paraffin microactuator," Transducers'99, vol. 2, pg. 1364-1367, 1999. 